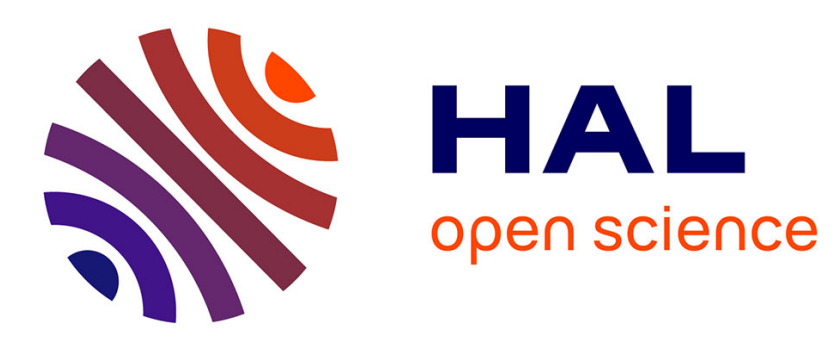

\title{
Recombination effects and impurity segregation at grain boundaries in polycrystalline silicon
}

\author{
S. Pizzini, A. Sandrinelli, M. Beghi, D. Narducci, P.L. Fabbri
}

\section{To cite this version:}

S. Pizzini, A. Sandrinelli, M. Beghi, D. Narducci, P.L. Fabbri. Recombination effects and impurity segregation at grain boundaries in polycrystalline silicon. Revue de Physique Appliquée, 1987, 22 (7), pp.631-636. 10.1051/rphysap:01987002207063100 . jpa-00245587

\section{HAL Id: jpa-00245587 https://hal.science/jpa-00245587}

Submitted on 1 Jan 1987

HAL is a multi-disciplinary open access archive for the deposit and dissemination of scientific research documents, whether they are published or not. The documents may come from teaching and research institutions in France or abroad, or from public or private research centers.
L'archive ouverte pluridisciplinaire HAL, est destinée au dépôt et à la diffusion de documents scientifiques de niveau recherche, publiés ou non, émanant des établissements d'enseignement et de recherche français ou étrangers, des laboratoires publics ou privés. 


\title{
Recombination effects and impurity segregation at grain boundaries in polycrystalline silicon
}

\author{
S. Pizzini, A. Sandrinelli, M. Beghi, D. Narducci and P. L. Fabbri (*) \\ Dept. of Physical Chemistry and Electrochemistry, University of Milan, via Golgi, 19, 20133 Milano, Italy \\ (*) Dept. of Physics, University of Modena, via Campi, 2, Italy
}

(Reçu le 27 novembre 1986, révisé le 20 janvier 1987, accepté le 10 février 1987)

\begin{abstract}
Résumé. - Les propriétés de recombinaison des joints de grains ont été étudiées de façon quantitative dans du silicium polycristallin dopé et non dopé. Une nouvelle méthodologie appliquée à l'analyse des signaux EBIC permet de comparer entre eux les résultats obtenus sur différents échantillons. Le problème des effets des impuretés et des défauts étendus sur la collecte des porteurs est alors considéré.
\end{abstract}

Abstract. - A quantitative account of the recombination properties of grain boundaries in undoped and impurity doped polycrystalline silicon is given, by analysing the results of EBIC measurements. These latter were carried out after having developed a new sampling methodology, which allows the intercomparison of EBIC results on a relative scale. The problem of synergistic carriers collection effects due to impurities and extended defects is also considered.

\section{Introduction.}

We have already shown in a previous paper [1] that the use of a zero order model - for which recombination of minority carriers in impurity doped polycrystalline materials occurs without significant interaction of impurities with grain boundaries (GB) - does apply only in the case of diluted solutions.

Actually, if we assume that no interaction occurs between impurities and GB, the diffusion length dependence on the impurities and microstructure might be described by an equation of the type [1] :

$$
L_{\mathrm{D}}=L_{\mathrm{D}}^{0}\left[1+\frac{N_{x}}{N_{x}^{0}}+\frac{N_{\mathrm{D}} L_{\mathrm{GB}}}{N_{s}^{0}}\right]^{-1 / 2}
$$

where $N_{x}$ is the concentration of impurity, $\left(N_{\mathrm{D}} \times L_{\mathrm{GB}}\right)$ is the product of the dislocation density $N_{\mathrm{D}}$ and of the GB length density $L_{\mathrm{GB}}$ and $N_{x}^{0}$, $N_{s}^{0}$ are constants.

In the practical circumstances, equation (1) holds - as one can observe in figure 1 , where the relative deviations from the model are reported as a function of the impurity concentration - only in the case of solutions containing less than $10^{12}$ to $10^{13} \mathrm{at} / \mathrm{cm}^{3}$, depending on the nature of each specific impurity.

While deviation from this model could be partially understood in the case of iron, by considering the formation of ionized (Fe-B) complexes [3], hardly they can be understood in the case of other impurities, without assuming substantial impurity-microstructure interactions.

Segregation of impurities at GB has been already demonstrated to occur in $\mathrm{Si}[3,6]$, also at bulk

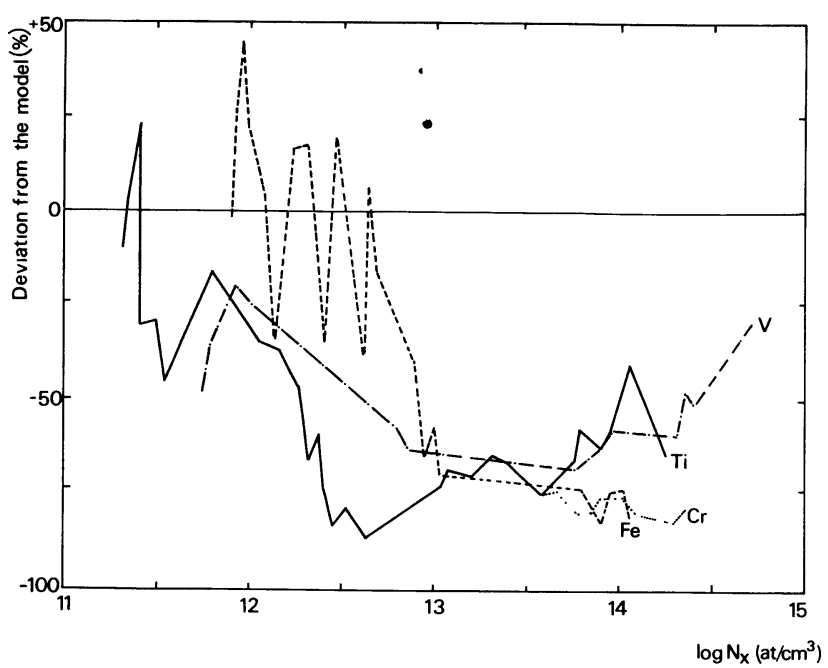

Fig. 1. - Deviation (\%) from the model (Eq. (1)) of the measured minority carriers diffusion length in impuritydoped polycrystalline silicon. 
concentrations well below their saturation concentration using both AES and SIMS techniques.

It comes out however from these measurements that the chemical bonding of impurities at GB could be either of the silicide or oxide type, depending on many experimental variables, including heat treatments to segregate oxygen at GB and absolute impurity concentration values.

As an example, while in concentrated multiple impurities silicon solutions, transition metals segregated at GB exhibit silicide bonding [6], in undoped silicon significant portion of hydrogen segregated at oxygen contains $\mathrm{GB}$, is chemically bonded with the hydroxil configuration [5].

Furthermore, also the electrical activity of GB seems to be dependent on the oxygen segregated on them. Duke et al. [7] showed, in fact, that the activation of GB is dependent on the heat treatments and tentatively proposed that the segregation of oxygen is responsible of the minority carriers losses. Eventually, also the spatial distribution of metal impurities seems to be strongly influenced by the presence of oxygen.

These latter findings fit quite well with recent results on the influence of heat treatments on the diffusion length of minority carriers in polycrystalline silicon, that cause a significant degradation of diffusion length, consequent to the heat treatments [1] and with still unpublished results [9] on the electrical activity of dislocations, which apparently increases with the increase of the oxygen content.

It turns out that the repartition of electrically active impurities between the volume of the sample and the extended defects is governed by a complex chemical equilibrium which includes both the interaction of impurities with oxygen into the bulk and at the extended defects (GB and dislocations) :

$$
\begin{aligned}
& \mathrm{O}_{\mathrm{i}} \leftrightharpoons \mathrm{O}_{\mathrm{D}} \leftrightharpoons \mathrm{O}_{\mathrm{GB}} \\
& \mathrm{Me}_{\mathrm{SS}}+\mathrm{O}_{\mathrm{i}} \leftrightharpoons \mathrm{Me}-\mathrm{O}_{\mathrm{GB}} \leftrightharpoons \mathrm{Me}-\mathrm{O}_{\mathrm{D}}
\end{aligned}
$$

- where $O_{i}$ is the oxygen dissolved in normal interstitial positions and the subscripts $\mathrm{D}, \mathrm{GB}$ and SS mean dislocations, grain boundaries and solid solution, respectively - and the interactions of oxygen with carbon, which are suggested to give rise to $(\mathrm{C}-\mathrm{O})$ complexes $[10,11]$.

It appears that the analysis of impurity doped samples must be implemented by the analysis of samples containing only native impurities and shallow dopants, in order to have a convenient reference system.

While in a previous paper [9] we have discussed the results of a detailed structural and electrical characterization of undoped polycrystalline samples, grown from electronic grade silicon by the directionally solidification technique, which apparently show that dislocations contribute more than GB to minori- ty carriers losses, we report and discuss in this present paper the results of some of our latest works on impurity doped polycrystalline silicon which includes also the assessment of a new methodology for reliably sampling polycrystalline materials by the EBIC technique.

\section{Experimental.}

Impurity doped polycrystalline samples were grown using the Czochralsky technique according to procedures already discussed in a earlier paper [1] and characterized for the influence of microstructure and of native impurities content on the electrical properties of minority carriers according to procedures already described in references $[1,9]$.

These latter include the determination of the diffusion length by the SPV technique, of the average and local dislocations and GB length density by optical means as well as the determination of the orientation of the single grains of a sample by the X$R$ precession technique and the specific crystallographic features of couples of grains by the use of their stereographic projections. Local recombination properties, instead, were measured using the EBIC technique, while employing a data acquisition methodology which slightly differ from the standard one, in order to have reliable intercomparison within samples belonging to different ingots.

The values of the EBIC contrast

$$
\frac{I^{0}-I_{\mathrm{GB}}}{I^{0}}
$$

- where $I^{0}$ is the generation current collected at a point sufficiently far from the $G B$ and $I_{\mathrm{GB}}$ is the current collected at GB - depend, in fact, on the absolute value of $I^{0}$, which is not necessary the same in undoped and impurity doped samples. On the other side, also the recombination rate calculated from the Donolato model $[11,13]$ using the values of the area and of the variance of the EBIC profile, is significative and useful for intercomparison purposes only provided the recombination properties of the bulk are not influenced by deep level impurities.

It turns out that unless measuring the values of $I^{0}$ for different samples on an absolute or relative scale, by making use of a reference sample, the comparison of the GB recombination properties is unpraticable, considering also that the EBIC current $I(x)$ is a very sensitive function of the electron beam current intensity $I_{\mathrm{b}}$, of the ohmicity of the front and back contacts on the samples and of the average current acquisition procedures, which in turn depend on the influence of the local generation efficiency $\eta(x)$ on the local microstructure and impurity concentration features :

$$
I(x)=\eta(x) \frac{E_{\mathrm{b}}}{c} I_{\mathrm{b}}+A
$$


- where $E_{\mathrm{b}}$ is the beam energy, $c$ is the average energy $(3.6 \mathrm{eV})$ required for the generation of an electron-hole couple and $A$ is a constant related to the thermal generation rate of carriers.

When $I_{\mathrm{GB}}$ is calculated by a fitting procedure of the experimental EBIC profile, a further problem arises when analysing samples containing impurities, as we cannot avoid in this case to implement the model used by Donolato [14] by considering not only the collection effects of the GB, represented by conditions of infinite surface recombination rate and, therefore, by a negligibly low charge density $p(x)$ :

$$
\begin{aligned}
p(x) & =0 \\
x & =0
\end{aligned}
$$

but also those relative to the impurities, whose concentration in the case of segregation is function of the distance from the boundary, considered as an infinite sink for them.

If we assume, however, that segregation at GB is capable to deplete completely the volume of the grains (case of dilute solutions of fast diffusing impurities), a very sharp concentration gradient sets up in coincidence with the boundary and the boundary condition (5) is still a valid approximation.

We could, therefore, investigate the influence of impurities on the volume and GB recombination by measuring the generation rate sufficiently far from GB $(I(x))$ and in coincidence with the GB $\left(I_{\mathrm{GB}}\right)$, while making use of the value of the current collected in a region of the sample where no injection in the p-n region could take place (as it is the thick ohmic contact region of the front) as the value of the constant $A$ of the equation (4) :

$$
\begin{aligned}
I_{\text {off }} & =A \\
I^{0}(x) & =I(x)-I_{\text {off }} .
\end{aligned}
$$

In these conditions, the difference $\left(I(x)-I_{\text {off }}\right)$ is the true measure of the generation current, which makes possible both a comparison of the recombination losses in different regions of a single sample and in different samples.

In the first case, in fact,

$$
I^{0}(x)=I(x)-I_{\text {off }}=a(x) I_{\mathrm{b}}
$$

where

$$
\begin{aligned}
a(x) & =\eta(x) \frac{E_{b}}{c} \\
I^{0}\left(x^{\prime}\right) & =I\left(x^{\prime}\right)-I_{\text {off }}=a\left(x^{\prime}\right) I_{\mathrm{b}}
\end{aligned}
$$

and

$$
\frac{I^{0}(x)}{I^{0}\left(x^{\prime}\right)}=\frac{a(x)}{a\left(x^{\prime}\right)}
$$

if the measure is taken in a time interval sufficiently short to ensure the constancy of $I_{b}$.

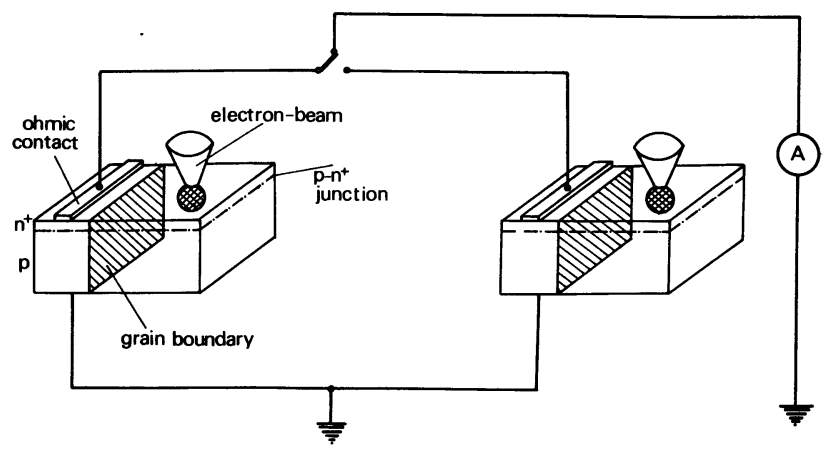

Fig. 2. - Schematic description of the sampling methodology used for measuring the EBIC current using a reference grain. $I_{\text {off }}$ is collected when the electron-beam impinges the thick ohmic contact. The shift of the sample from one to other position is carried out by means of a micrometer.

In the second case, the use of a sample holder of the type schematically illustrated in figure 2 , which permits to shift the electron beam from the sample $A$ to the sample B, does allow to compare the local recombination properties by mean of the ratio

$$
I_{\mathrm{A}}^{0}(x) / I_{\mathrm{B}}^{0}\left(x^{\prime}\right) .
$$

Of course, both ratios (8) and (9) are functions of the local properties of the material and a statistical analysis of the distribution of the ratios values between the bulk of the different grains should allow an evaluation of the homogeneity of the electrical properties in the volume of the grains.

Eventually, by selecting a specific region of a certain sample as the internal reference state of the current $I_{\text {ref }}$, the ratios

$$
\frac{I_{\mathrm{A}}^{0}(x)}{I_{\mathrm{ref}}^{0}}=\frac{I_{\mathrm{B}}^{0}\left(x^{\prime}\right)}{I_{\mathrm{ref}}^{0}} \cdots
$$

are a measure of the recombination losses of different samples, on a relative scale, as they are independent of fluctuations of $I_{\mathrm{b}}$, if the measure of $I(x)$ and $I_{\text {ref }}$ is taken in close sequence.

In quite an analogous manner, the GB properties could be evaluated by fitting the EBIC profile in order to determine the value $I_{\mathrm{GB}}$ of the current collected in correspondence to the GB, and then the value of the contrast :

$$
\frac{I_{\infty}^{0}-I_{\mathrm{GB}}^{0}}{I_{\infty}^{0}} .
$$

Here

$$
I_{\mathrm{GB}}^{0}=I_{\mathrm{GB}}-I_{\mathrm{off}}
$$

and

$$
I_{\infty}^{0}=I^{0}(x=\infty)-I_{\text {off }}
$$


while $I^{0}(x=\infty)$ is the value of the current calculated by an exponential fitting of the tails of the experimental EBIC profile.

This latter should be very close to the value of $I^{0}(x)$ determined by collecting the EBIC current in the centre of the grain neighbour to the GB considered, unless the grain size is too small.

\section{Experimental results.}

A preliminary evaluation of the advantages of the procedure described in the last section has been carried out by measuring the average values and the standard deviations of the ratio (8), using the values of the current $I_{\mathrm{A}}^{0}(x)$ and $I_{\mathrm{B}}^{0}(x)$ collected on a small area at the centre of two grains belonging to two different samples A and B, of which one is selected as the standard.

In these measurements the conditions of injection were varied $\left(I_{\mathrm{b}}\right.$ varied between 100 and $\left.250 \mathrm{pA}\right)$ as well as the collection time (measured in $10^{-3}$ s/line-scan), while the number of individual local current measured by sequential scans of the area was maintained constant and close to 5000 .

In order to determine the sensitivity of the measure to the nature of the front contact (an evaporated Ti-Pd-Ag contact), a few measurements were carried out using a couple of different contacts.

The results are reported in table I, which shows the very narrow distribution of the ratios $I_{\text {grain }}^{0} / I_{\text {standard }}^{0}(0.938 \pm 0.023)$ obtained when using the contact $\mathrm{n}^{\circ} 1$ and the non negligible influence of the use of another contact, which brings the value of the ratio $I_{\text {grain }}^{0} / I_{\text {standard }}^{0}$ slightly, but non negligibly, out of the range.

Using the same methodology, we have collected the values of the ratio (9) for different grains of an undoped sample using one grain of the same sample as the reference. For several grains of two doped samples (one Ti-doped and one Fe-doped) whose average properties are reported in table II, we used, as the reference, the grain utilised as the standard one in the undoped sample.

The results are reported in table III, which shows not only that the standard deviation from the average value is narrower in the doped samples but also that the recombination losses in the volume of the grains of the doped samples are $30 \%$ less than those observed in the undoped sample, independently of the nature of the impurity considered.

In order to account for these results it is not only necessary to assume that segregation at GB does occur in doped samples, leaving the bulk of the grain clean, but also that recombination losses in the bulk

Table II. - Average physical and chemical properties of the samples investigated with EBIC measurements.

\begin{tabular}{|c|c|c|c|c|}
\hline Sample & Dopant & $\begin{array}{c}N_{x} \\
\left(\mathrm{at} / \mathrm{cm}^{3}\right)\end{array}$ & $\begin{array}{c}L_{\mathrm{D}} \\
(\mu \mathrm{m})\end{array}$ & $\underset{\left(\mathrm{cm}^{-2}\right)}{N_{\mathrm{D}}}$ \\
\hline - & - & - & - & - \\
\hline F20-51 & $\mathrm{Ti}$ & $1.8 \times 10^{12}$ & 60 & $8.8 \times 10^{4}$ \\
\hline-24 & $\mathrm{Fe}$ & $6.3 \times 10^{13}$ & 32 & $1.1 \times 10^{5}$ \\
\hline SF4-24 & $\mathrm{Fe}$ & $9.3 \times 10^{12}$ & 30 & $3.0 \times 10^{5}$ \\
\hline DS-W221-56c & undoped & & 200 & $2.3 \times 10^{4}$ \\
\hline
\end{tabular}

Table I. - Experimental values of EBIC currents collected on two grains belonging to the samples SF20-51 and SF13-24 (standard) under different experimental conditions.

\begin{tabular}{|c|c|c|c|c|c|c|c|}
\hline & $\begin{array}{c}I \\
\text { (a.u.) } \\
-\end{array}$ & $\begin{array}{c}I_{\text {off }} \\
\text { (a.u.) }\end{array}$ & $\begin{array}{c}I^{0} \\
\text { (a.u.) }\end{array}$ & $\begin{array}{c}I^{0} \text { grain } / \\
I^{0} \text { standard }\end{array}$ & $\begin{array}{c}\text { Acquisition } \\
\text { Time (ms/scan) }\end{array}$ & $\begin{array}{c}I_{\mathrm{b}} \\
(\mathrm{pA})\end{array}$ & $\begin{array}{l}\text { Ohmic } \\
\text { Contact }\end{array}$ \\
\hline Standard grain & $\begin{array}{l}2229.68 \\
2212.37\end{array}$ & $\begin{array}{l}1860.54 \\
1850.51\end{array}$ & $\begin{array}{l}369.14 \\
361.86\end{array}$ & 0.980 & $\overline{125}$ & $\overline{100}$ & $\overline{1}$ \\
\hline Standard grain & $\begin{array}{l}2243.36 \\
2197.98\end{array}$ & $\begin{array}{l}1895.79 \\
1870.73\end{array}$ & $\begin{array}{l}347.57 \\
327.25\end{array}$ & 0.942 & 32 & 100 & 1 \\
\hline Standard grain & $\begin{array}{l}2248.65 \\
2196.21\end{array}$ & $\begin{array}{l}1893.66 \\
1868.82\end{array}$ & $\begin{array}{l}354.99 \\
327.39\end{array}$ & 0.922 & 32 & 100 & 1 \\
\hline Standard grain & $\begin{array}{l}2198.11 \\
2194.07\end{array}$ & $\begin{array}{l}1850.16 \\
1874.90\end{array}$ & $\begin{array}{l}347.95 \\
319.17\end{array}$ & 0.917 & 32 & 100 & 1 \\
\hline Standard grain & $\begin{array}{l}2240.67 \\
2219.57\end{array}$ & $\begin{array}{l}1898.86 \\
1898.14\end{array}$ & $\begin{array}{l}341.81 \\
321.43\end{array}$ & 0.940 & 32 & 100 & 1 \\
\hline Standard grain & $\begin{array}{l}2264.88 \\
2227.96\end{array}$ & $\begin{array}{l}1876.11 \\
1867.72\end{array}$ & $\begin{array}{l}388.77 \\
360.24\end{array}$ & 0.927 & 32 & 250 & 1 \\
\hline $\begin{array}{l}\text { Ave. } \\
\text { St. Dev. }\end{array}$ & & & & $\begin{array}{l}0.938 \\
0.021\end{array}$ & & & \\
\hline Standard grain & $\begin{array}{l}2279.00 \\
2267.97\end{array}$ & $\begin{array}{l}1852.46 \\
1882.53\end{array}$ & $\begin{array}{l}426.54 \\
385.44\end{array}$ & 0.904 & 32 & 250 & 2 \\
\hline
\end{tabular}


Table III. - Average values of the EBIC current of the samples DS-W221-56a (undoped), SF20-51 (Ti-doped) and SF13-24 (Fe-doped).

\begin{tabular}{|c|c|c|c|c|c|}
\hline Sample & $\begin{array}{c}I \text { grain } \\
\text { (a.u.) }\end{array}$ & $\begin{array}{c}I_{\text {off }} \\
\text { (a.u.) }\end{array}$ & $\begin{array}{c}I^{0} \text { grain } \\
\text { (a.u.) }\end{array}$ & $\begin{array}{c}I^{0} \text { grain } / \\
I^{0} \text { standard }\end{array}$ & Remarks \\
\hline & - & - & - & - & - \\
\hline DS-W221-56a & $2278.96 \pm 50$ & 1787.55 & 491.41 & 0.97 & $\begin{array}{c}\text { Average on } \\
7 \text { grains }\end{array}$ \\
\hline SF20-51 & $2252.70 \pm 5$ & 1849.03 & 403.67 & 1.29 & $\begin{array}{l}\text { Average on } \\
8 \text { grains }\end{array}$ \\
\hline SF13-24 & $2261.62 \pm 4$ & 1733.85 & 527.77 & 1.30 & $\begin{array}{c}\text { Average on } \\
3 \text { grains }\end{array}$ \\
\hline
\end{tabular}

of the doped samples are less because dislocations, which are electrically active in the undoped samples, due to oxygen segregated on them, are inactivated by impurity segregation due to the formation of impurity-oxygen complexes [9]. Incidentally, this conclusion is well in agreement with that already rised by Salama [15] and Martinuzzi [16] about the disactivation of extended defects by impurity segregation.

However, as recombination losses in the volume of the grains of doped and undoped samples are, in this particular case, demonstrated to be comparable within a factor of 0.3 , it turns out that both the contrast and recombination rate figures, determined by standard procedures with the EBIC technique, are useful for sample intercomparison purposes.

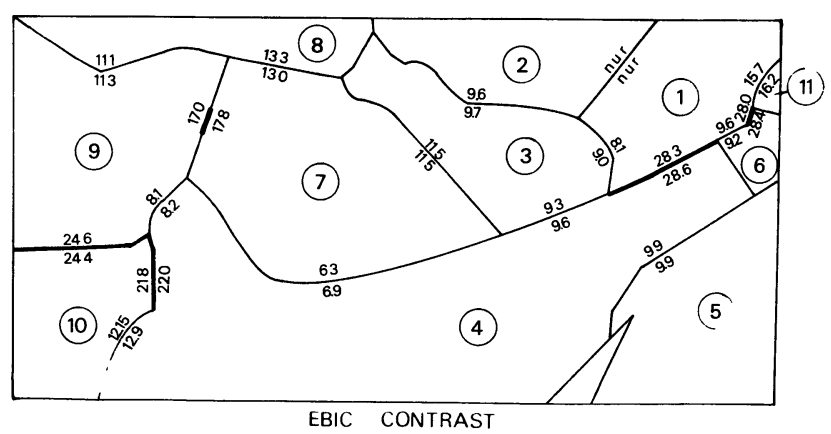

Fig. 3. - EBIC contrast map of the SF20-51 sample (Tidoped). Heavier lines indicate region of strong recombination.
A detailed analysis of the Ti-doped and Fe-doped samples was therefore carried out by systematically scanning each GB on points lying at an average distance of $100 \mu \mathrm{m}$.

Results are reported in the EBIC contrast map in figure 3 for the Ti-doped sample, where the EBIC contrast figures are displayed as average values.

By comparing these results with those already obtained on the undoped sample [9] and reported in figure 4 , one could remark first that, in average, most of the GB in the Ti-doped and in the undoped sample present comparable values of EBIC contrast.

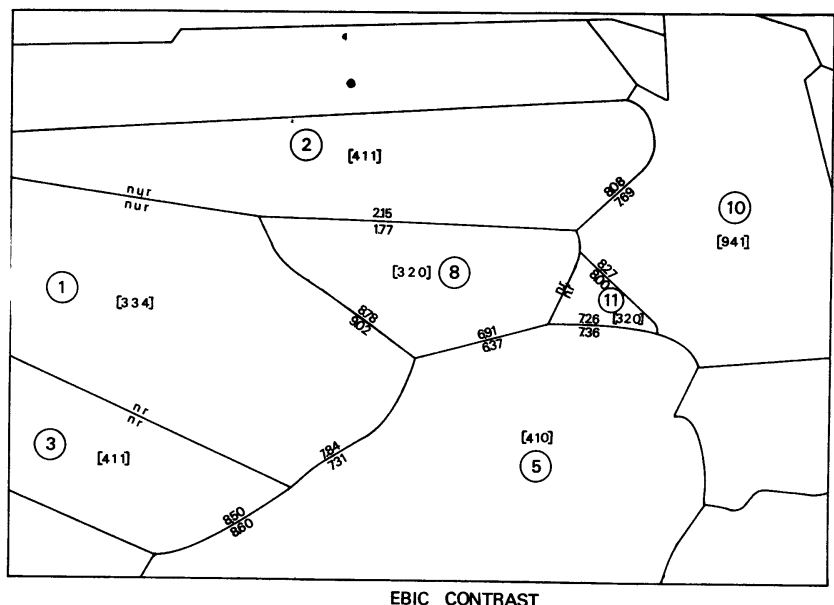

Fig. 4. - EBIC contrast map of the DS-W221-56c sample (undoped). Figures in brackets show the grain orientation.

Table IV. - Recombination rate and EBIC contrast for some grain boundaries of the sample SF4-24 (9.2 $\times$ $10^{12} \mathrm{at} / \mathrm{cm}^{3}$. Fe-doped).

\begin{tabular}{cccccc} 
Grain & $\begin{array}{c}\text { Scan } \\
\text { nr. }\end{array}$ & $\begin{array}{c}\text { Recombination } \\
\text { Rate (left) } \\
(1 \mathrm{E} 4 \mathrm{~cm} / \mathrm{s})\end{array}$ & $\begin{array}{c}\text { Recombination } \\
\text { Rate }(\text { right }) \\
(1 \mathrm{E} 4 \mathrm{~cm} / \mathrm{s})\end{array}$ & $\begin{array}{c}\text { EBIC } \\
\text { contrast } \\
(\text { left })(\%)\end{array}$ & $\begin{array}{c}\text { EBIC } \\
\text { contrast } \\
\text { (right) }(\%)\end{array}$ \\
\hline a & - & - & - & - & - \\
b & 1 & 19.5 & 11.6 & 21.6 & 21.6 \\
c & 1 & 13.1 & 27.6 & 27.9 & 27.9 \\
& 1 & 22.5 & 32.3 & 27.9 & 27.9
\end{tabular}


Few GB in the Ti-doped sample, instead, present contrast figures which are, at least, larger of a factor of 3 .

Furthermore, while the contrast is essentially uniform along each specific GB in the undoped sample [9], large inhomogeneities are observed in Ti-doped sample.

Albeit the case of Fe-doped samples deserves further experimental attention, as the SF13-24 sample, which was examined in great detail, is heavily twinned with only few recombining GB, it seems however, looking to the results reported in table IV, which refers to a second Fe-doped sample (SF4-24) presenting comparable values of iron dope, that iron behaves like titanium.

\section{Summary and conclusion.}

As already mentioned in the introduction section, we have demonstrated in a previous paper [9] that the minority carriers losses in undoped, polycrystalline silicon grown by the directionally solidification technique mostly depend on the recombination at dislocations, the GB contributing only slightly to the overall recombination losses. We have also demonstrated that the electrical activity of dislocations increases with the oxygen concentration, thus providing a strong support to the view of Duke et al. [7], who suggested that segregation of oxygen at dislocations is responsible of minority carriers losses.

The essential difference between the undoped and the doped samples studies in the present work is that, in spite of the lower average values of the diffusion length measured on the undoped samples using the SPV technique (see Table II), the intergrain recombination losses determined by measuring locally the EBIC current are less important in undoped samples. It turns out that the few GB that are electrically active in the doped samples are responsible of the major minority carriers recombination losses, but it remains totally undetermined why segregation occurs only on specific GB. A second, essential difference between the samples examined is that volume recombination is less in doped samples.

Considering that all the samples analysed have comparable dislocation densities (see Table II), one should conclude that deep-level impurities gettered at dislocations via $\mathrm{Me}-\mathrm{O}$ bonds make those dislocations less recombining that dislocations decorated only with oxygen in the undoped material.

These conclusions, which well agree with previous results of Salama [15] and Martinuzzi [16] concerning the interaction of metallic impurities, oxygen and intergrain defects in silicon, need however further DLTS and SIMS evidence in order to be considered definitive.

\section{Acknowledgments.}

The authors warmly acknowledge the friendly cooperation of Prof. P. G. Ottaviani, Dept. of Physics, University of Modena. This work has been entirely supported by the CNR-ENEA Progetto Finalizzato Energetica II.
[1] Pizzini, S., Bigoni, L., Beghi, M., Chemelli, C., J. Electrochem. Soc. 133 (1986) 2363.

[2] Graff, K., PiePer, H., J. Electrochem. Soc. 128 (1981) 669.

[3] Kasmerski, L. L., Ireland, P. J., CizeK, T. K., Appl. Phys. Lett. 36 (1980) 323.

[4] Kasmerski, L. L., Russel, P. E., J. Physique Colloq. 43 (1982) C1, 171.

[5] KASMERSKi, L. L., Proc. 6th E.C. Photovoltaic Solar Energy Conf. (1985) (D. Reidel Publ., Dordrecht), p. 83.

[6] Pizzini, S., Braicovich, L., Calliari, L., GasPARINI, M., MARI, C. M., REdAElli, F., SANCROTTI, M., Proc. 4th E.C. Photovoltaic Solar Energy Conf. (1982) (D. Reidel Publ., Dordrecht), p. 874

[7] Duke, C., Hanoka, J. I., Sandstrom, H. L., Appl. Phys. Lett. 44 (1983) 425.
[8] Deville, J. P., Quesada, J., Soltani, M. L., J. Physique Colloq. 43 (1981) C1, 193.

[9] Pizzini, S., SANdrinelli, A., Beghi, M., NarDUCCI, D., Allegretti, F., Torchio, S., FABBRi, P. L., OtTaViani, G. P., Demartin, F., FUSI, A., J. Electrochem. Soc. (in press).

[10] Newman, R. C., Smith, R. S., J. Phys. Chem. Solids 30 (1969) 1493.

[11] Bean, A. R., Newman, R. C., J. Phys. Chem. Solids 33 (1972) 255.

[12] Donolato, C., J. Phys. St. Sol. 65 (1981) 649.

[13] Donolato, C., J. Phys. St. Sol. 66 (1981) 445.

[14] Donolato, C., J. Appl. Phys. 54 (1983) 1314.

[15] Salama, A. M., J. Electrochem. Soc. 126 (1979) 114.

[16] Martinuzzi, S., Proc. 18th IEEE Photovoltaic Specialist Conf. (1986) p. 1127. 